\title{
Hip Restricted Range of Motion in Physical Examination: A Possible Risk Factor For Non-Contact ACL Injury
}

\author{
Abolfazl Bagherifard ${ }^{1}$; Mahmoud Jabalameli ${ }^{1}$; Kaveh Gharanizadeh ${ }^{1}$; Ali Jahansooz ${ }^{1}$; Faeze \\ Abbasi ${ }^{1}$; Milad Haji Agha Bozorgi ${ }^{1}$; Hooman Yahyazadeh ${ }^{1,}$ \\ ${ }^{1}$ Bone and Joint Reconstruction Research Center, Shafa Orthopedic Hospital, Iran University of Medical Sciences, Tehran, IR Iran \\ *Corresponding author: Hooman Yahyazadeh, Bone and Joint Reconstruction Research Center, Shafa Orthopedic Hospital, Iran University of Medical Sciences, Tehran, IR Iran. \\ Tel : +98-2188934256, Fax: +98-2133542020, E-mail: yahyazadeh59@gmail.com
}

Received: May 22, 2015; Revised: June 15, 2015; Accepted: July 10, 2015

\begin{abstract}
Background: There is significant evidence of hip and knee kinematic influence on each other. In some studies, hip restricted range of motion is a risk factor of anterior cruciate ligament (ACL) tear.

Objectives: This study was designed to compare hip range of motion in physical examination between non-contact ACL injured patients with normal population.

Patients and Methods: One hundred and forty patients with arthroscopically confirmed primary ACL ruptures were evaluated to assess their hip range of motion; these findings were compared with a control group of 100 patients with non ACL injury.

Results: All parameters of hip range of motion (internal rotation, abduction and adduction) except external rotation were decreased significantly in ACL injured group compared with control group. Patients with sum of internal and external rotation lower than $80^{\circ}$ had an increased odds ratio of having ACL injuries ( $\mathrm{OR}=2.64 ; 95 \% \mathrm{CI}, 1.4$ to 4.7$)$.

Conclusions: There was an association between non-contact ACL rupture and decreased hip range of motions including internal rotation, abduction and adduction as well as sum of internal and external rotation. Therefore, it may be possible to use hip physical exam finding as a predictor of ACL rupture.
\end{abstract}

Keywords: Anterior Cruciate Ligament; Tear; Motion; Knee

\section{Background}

One of the most challenging events competent to put an end to an athlete's professional life is noncontact rupture of the anterior cruciate ligaments (ACLs). There is large number of studies that focus on the surgical management of noncontact ACL rupture; on the other hand, there is fewer studies that investigate preventing and predisposing anthropomorphic factors (1-3). Anterior cruciate ligament injury in athletes has a multi-factorial etiology. Some of risk factors for ACL rupture are preventable by some change in environment and training athlete, for example during landing or pivoting (4-7).

Influence of hip and knee biomechanics on each other has been shown by several studies $(1,4,5)$. Hip physical examination and assessment is very important in operation planning during ACL reconstruction (5). Recent studies mentioned the complex structural anatomic variants of the hip joint like femoral or acetabular retroversion, femoral notch geometry, extraarticular impingement and femoroacetabular impingement that are associated with restriction in internal rotation of the hip, which can result in increased risk of ACL injury $(4,6,8,9)$. Femoroacetabular impingement (FAI) is one of the main causes of restriction in hip range of motion, particularly internal rotation $(8,10)$. Therefore, FAI can increase resistance to femoral internal axial rotation during a dynamic maneuver such as a pivot landing and cause ACL rupture (4).

Restriction in hip range of motion results in greater ACL strain, so more ACL rupture prevalence is seen in this population $(4,5,11)$. Most biomechanical studies on anterior cruciate ligament injury are limited to data and research performed in laboratory (12). Video analysis and radiography yield better information about biomechanical and biological relation between hip, knee, ankle and their related pathology (12-14). Future research strategies are aimed to find a simple method to find risk factors of anterior cruciate ligament injury to provide better prevention programs to decrease serious injury, but main factors playing a role in this event are still debatable $(6,7)$.

\section{Objectives}

This study was designed to evaluate the effect of hip range of motion restriction measured by physical examination in noncontact ACL ruptures in patients with surgically confirmed ACL ruptures and comparing it with normal population. 


\section{Patients and Methods}

In this retrospective study, 140 patients with arthroscopically confirmed primary ACL ruptures caused by noncontact trauma were evaluated to assess their hip range of motion and comparing findings with a control group including 100 patients with non ACL injury.

All knee pathology was confirmed with knee arthroscopy. The exclusion criteria were previous knee or hip surgery (except recent ACL surgical reconstruction), any impairments, pain or complaints affecting the lower limb outside the knee joints and valgus or varus deformity.

All patients in both groups underwent history taking and physical examination by one of the two orthopedic surgeons. None of the individuals in control group had the history of previous knee or hip surgery or pelvic pain in examination.

The examination of hip range of motion in all participants performed two times separately by the same two members of the orthopedic staff of the hospital to avoid intra and inter observer measurement errors. All patients lied on their backs in supine position and examiners assessed range of motion of internal and external rotation at $90^{\circ}$ of hip flexion and hip abduction and adduction assessed when the hip was extended. In this study, external manual goniometer was used for measurement of parameters based on degrees with $0^{\circ}$ as neutral. Limits were established based on the first pelvic tilt displacement in a fully relaxed individual.

The study was approved by the ethic committee of Iran university of medical sciences. All study participants signed inform consent forms.

\subsection{Statistical Analysis}

Statistical analyses were performed using IBM SPSS 22 statistical software (SPSS Inc, Chicago, Illinois, the United States). Quantitative variables were compared using Ttest. Chi-square tests of the categorical variable were conducted to determine significance.
Odds ratios and $95 \%$ confidence intervals were produced in all analyses. An alpha level of 0.05 was considered significant for all tests.

\section{Results}

Finally, 127 patients and 90 normal population included in statistical analysis. Demographic characteristics of subjects in each study group are presented in Table 1 with no differences in demographic parameters such as age, gender distribution, height, weight and BMI (body mass index).

In ACL-injured group, 50.4\% had the right knee injury, $44.1 \%$ had the left and in $5.5 \%$ of patients both knees were injured.

Football playing was the most common cause of injury (47.2\%), the second one was running (23.2\%), third one was volleyball or basketball (15.2\%), then wrestling (11.2\%) and the other causes were $3.2 \%$.

As shown in Table 2, all of the parameters of hip range of motion (internal rotation, abduction and adduction) except external rotation ( $\mathrm{P}=0.86$ ), decreased significantly in ACL injured group compared with the control group.

In addition, our findings showed a significant decrease in the sum of internal rotation and external rotation on injured side $(\mathrm{P}<0.001)$. The sum of internal and external rotation was categorized by cutoff point of $80^{\circ}$; the value lower than cut point suggested a decrease in hip range of motion and 2.64 times more likely ( $\mathrm{OR}=2.64$; 95\% CI, 1.4 to 4.7 ) to be in the ACL-injured group than those patients with the sum of $80^{\circ}$ or more $(\mathrm{P}=0.001)$.

In the ACL-injured group, $50.4 \%(n=64)$ of patients had a decrease in hip range of motion, while only $27.8 \%$ ( $n=$ 25) of control group had a similar decrease.

As hypothesized, our findings showed an association between noncontact ACL rupture and decreased hip range of motions including internal rotation, abduction and adduction as well as sum of internal and external rotation.

Table 1. Age, Sex, Height, Weight and Body Mass Index in ACL Injured and Non-ACL Injured Patients a,b

\begin{tabular}{|c|c|c|c|}
\hline & ACL Injured & Non-ACL Injured & P Value \\
\hline Number of patients & 127 & 90 & \\
\hline Age, $y$ & $27.8 \pm 6.1$ & $28.9 \pm 6.3$ & $<0.05$ \\
\hline Gender & & & $<0.05$ \\
\hline Male & 114 & 79 & \\
\hline Female & 13 & 11 & \\
\hline Height, cm & $175.0 \pm 7.7$ & $176.7 \pm 5.4$ & $<0.05$ \\
\hline Weight, kg & $78.2 \pm 10.5$ & $77.8 \pm 9.5$ & $<0.05$ \\
\hline BMI, $\mathrm{Kg} / \mathrm{m}^{2}$ & $25.4 \pm 2.7$ & $24.8 \pm 2.2$ & $<0.05$ \\
\hline
\end{tabular}

a Abbreviations: ACL, anterior cruciate ligament; BMI, body mass index.

$\mathrm{b}$ Data are presented as mean \pm SD. 
Bagherifard A et al.

\begin{tabular}{|c|c|c|c|}
\hline & ACL Injured & Non-ACL Injured & P Value \\
\hline Mean internal rotation & $33.5 \pm 13.3$ & $40.3 \pm 10.5$ & $<0.001$ \\
\hline Mean external rotation & $49.4 \pm 8.0$ & $49.6 \pm 7.0$ & 0.86 \\
\hline $\begin{array}{l}\text { Sum of internal and exter- } \\
\text { nal rotation }\end{array}$ & $83.0 \pm 14.8$ & $90.0 \pm 13.4$ & $<0.001$ \\
\hline Mean abduction & $32.0 \pm 8.1$ & $38.5 \pm 7.0$ & $<0.001$ \\
\hline Mean adduction & $22.4 \pm 7.8$ & $28.9 \pm 5.4$ & $<0.001$ \\
\hline
\end{tabular}

a Abbreviation: ACL, anterior cruciate ligament.

$\mathrm{b}$ Data are presented as mean \pm SD.

\section{Discussion}

Although most of non-contact knee injuries were treated alone as a traumatic event in clinical practice, lower and upper parts could affect knee functional biomechanics hip and ankle have a significant role in knee biomechanics $(1,6,10-12,15,16)$.

In this study, patients with ACL knee injuries had decrease in their hip range of motion parameters such as internal rotation $\left(33.5^{\circ}\right.$ vs $\left.40.3^{\circ} ; \mathrm{P}<0.001\right)$, abduction $\left(32^{\circ}\right.$ vs $\left.38.5^{\circ}: \mathrm{P}<0,001\right)$, adduction $\left(22.4^{\circ}\right.$ vs $28.9^{\circ} \mathrm{P}<$ $0.001)$ and also sum of internal and external rotation $\left(83^{\circ}\right.$ vs $\left.90^{\circ} ; \mathrm{P}<0.001\right)$. Patients with sum of internal and external rotation lower than $80^{\circ}$ had an increased odds ratio of having ACL injuries ( $\mathrm{OR}=2.64 ; 95 \% \mathrm{CI}, 1.4$ to 4.7 ).

Lopes et al. compared hip range of motion between the two groups of ACL contact injured patients with ACL non-contact injured ones. They showed that the sum of hip internal and external rotation was greater in patients with ACL injury in contact mechanism compared to noncontact ACL inured group $\left(66.1 \pm 8.4^{\circ}\right.$ compared to $79.4 \pm$ $\left.10.6^{\circ} ; \mathrm{P}<0.001\right)$. Seventy-seven percent of patients in the non-contact group had a sum of hip rotation $<70^{\circ}$ and $93 \%$ had $<80^{\circ}$, compared to $17.1 \%$ and $42.9 \%$ in the contact group ( $\mathrm{P}<0.001)$. They reported that patients with contact ACL injury had a greater ROM of hip joints than those with non-contact ACL injury (15).

Gomes et al. evaluated hip range of motion in 50 male soccer players with non-contact ACL injuries compared with control group of unaffected 50 male soccer players. As our findings, they reported that all hip range of motion parameters decreased in patients with ACL rupture except for mean external rotation. They believed that decreased internal rotation was the main reason for loss of motion in these soccer players (1).

Bedi et al. measured hip range of internal rotation in 324 football athletes and correlated with a history of ACL injury and surgical repair. This cross-sectional study showed that a reduction in internal rotation of the left hip was associated with statistically significant increased odds of ACL injury in the ipsilateral or contralateral knee. They showed that $30^{\circ}$ reduction in left hip internal rota- tion was associated 4.06 times more odds of ACL injury in ipsilateral and 5.29 times greater in contralateral limbs (4). Our study showed 2.64 times greater odds in ACL injury in patients with less than 80 degree of hip internal and external rotation.

A recent meta-analysis study underlined the multi-factorial nature of noncontact ACL injuries and urgent need to identify new risk factors to improve prevention (7).

Several studies, especially video analysis in sport injuries, significantly demonstrated a relation between hip and knee kinematic, which can affect increasing ACL strain. This greater strain is the main cause of ACL rupture in these patients $(11,13-15)$. Decrease in hip range of motion is multifactorial, one of the most important factors in femoroacetabular impingement which can cause restriction in hip range of motion, especially internal rotation, so can cause increase in ACL strain during landing and pivoting $(8,9)$. Philippon showed a significant decrease in hip offset in ACL injured patients (9).

Finally, hip physical exam can be a valuable measurement tool in prediction of ACL injury. Physical examination and some training in landing and pivoting maneuver in those with restriction in hip motion may decrease ACL rupture during sport seasons.

Hip range of motion evaluation should become a routine part of surgical decision-making process in ACL injured patients $(1,5)$.

However our study was performed on a relatively large number of patients, it certainly had some limitations. Although the gender distribution was balanced between groups, a greater proportion of males were participated, so this makes it difficult to generalize the results to females and retrospective nature of study was the other limitation factor.

\section{Authors' Contributions}

Study concept and design: Mahmoud Jabalameli, Abolfazl Bagherifard and Kaveh Gharanizadeh. Analysis and interpretation of data: Hooman Yahyazadeh and Ali Jah- 
ansooz. Drafting of the manuscript: Abolfazl Bagherifard, Mahmoud Jabalameli, Kaveh Gharanizadeh, Ali Jahansooz, Faeze Abbasi, Milad Haji Agha Bozorgi and Hooman Yahyazadeh. Critical revision of the manuscript for important intellectual content: Abolfazl Bagherifard and Kaveh Gharanizadeh. Study supervision: Mahmoud Jabalameli, Abolfazl Bagherifard and Kaveh Gharanizadeh.

\section{References}

1. Gomes JL, de Castro JV, Becker R. Decreased hip range of motion and noncontact injuries of the anterior cruciate ligament. Arthroscopy. 2008;24(9):1034-7.

2. Biau DJ, Katsahian S, Kartus J, Harilainen A, Feller JA, Sajovic M, et al. Patellar tendon versus hamstring tendon autografts for reconstructing the anterior cruciate ligament: a meta-analysis based on individual patient data. Am J Sports Med. 2009;37(12):2470-8.

3. Yunes M, Richmond JC, Engels EA, Pinczewski LA. Patellar versus hamstring tendons in anterior cruciate ligament reconstruction: A meta-analysis. Arthroscopy. 2001;17(3):248-57.

4. Bedi A, Warren RF, Wojtys EM, Oh YK, Ashton-Miller JA, Oltean $\mathrm{H}$, et al. Restriction in hip internal rotation is associated with an increased risk of ACL injury. Knee Surg Sports Traumatol Arthrosc. 2014

5. Ellera Gomes JL, Palma HM, Ruthner R. Influence of hip restriction on noncontact ACL rerupture. Knee Surg Sports Traumatol Arthrosc. 2014;22(1):188-91.

6. Posthumus M, Collins M, September AV, Schwellnus MP. The intrinsic risk factors for ACL ruptures: an evidence-based review. Phys Sportsmed. 2011;39(1):62-73.

7. Alentorn-Geli E, Mendiguchia J, Samuelsson K, Musahl V, Karls- son J, Cugat R, et al. Prevention of anterior cruciate ligament injuries in sports. Part I: systematic review of risk factors in male athletes. Knee Surg Sports Traumatol Arthrosc. 2014;22(1):3-15.

8. Pollard TC, Villar RN, Norton MR, Fern ED, Williams MR, Simpson DJ, et al. Femoroacetabular impingement and classification of the cam deformity: the reference interval in normal hips. Acta Orthop. 2010;81(1):134-41.

9. Philippon M, Dewing C, Briggs K, Steadman JR. Decreased femoral head-neck offset: a possible risk factor for ACL injury. Knee Surg Sports Traumatol Arthrosc. 2012.

10. Williams JG. Limitation of hip joint movement as a factor in traumatic osteitis pubis. BrJ Sports Med. 1978;12(3):129-33.

11. Lawrence R3, Kernozek TW, Miller EJ, Torry MR, Reuteman P. Influences of hip external rotation strength on knee mechanics during single-leg drop landings in females. Clin Biomech (Bristol, Avon). 2008;23(6):806-13.

12. Boden BP, Torg JS, Knowles SB, Hewett TE. Video analysis of anterior cruciate ligament injury: abnormalities in hip and ankle kinematics. Am J Sports Med. 2009;37(2):252-9.

13. Hewett TE, Myer GD, Ford KR. Anterior cruciate ligament injuries in female athletes: Part 1 , mechanisms and risk factors. Am J Sports Med. 2006;34(2):299-311.

14. Ellera Gomes JL, Palma HM, Becker R. Radiographic findings in restrained hip joints associated with ACL rupture. Knee Surg Sports Traumatol Arthrosc. 2010;18(11):1562-7.

15. Lopes OJ, Gomes JL, de Freitas Spinelli L. Range of motion and radiographic analysis of the hip in patients with contact and non-contact anterior cruciate ligament injury. Knee Surg Sports Traumatol Arthrosc. 2015.

16. Beaulieu ML, Oh YK, Bedi A, Ashton-Miller JA, Wojtys EM. Does limited internal femoral rotation increase peak anterior cruciate ligament strain during a simulated pivot landing? Am J Sports Med. 2014;42(12):2955-63. 